\title{
Políticas de formação de professores: construindo resistências
}

\section{Teacher training policies:}

building resistance

\section{Políticas de capacitación docente: construyendo resistencias}

\author{
KÁTIA AUGUSTA CURADO PINHEIRO CORDEIRO DA SILVA* \\ Universidade de Brasília, Brasília- DF, Brasil.
}

RESUMO: O texto analisa as políticas campo da formação, propostas no atual Governo Federal (2016-2018), com foco no programa de Residência Pedagógica. O programa se orienta pelo pragmatismo na concepção de formação de professores. Aponta-se para alguns elementos de crítica aos programa, indicando elementos de resistência para uma política de formação e profissionalização dos trabalhadores da educação, na epistemologia da práxis, nos termos defendidos pela área de Educação e pela Associação Nacional pela Formação dos Profissionais da Educação (Anfope).

Palavras-chave: Formação de Professores. Políticas educacionais. Epistemologia da práxis.

\begin{abstract}
The text analyzes the field training policies, proposed in the current Federal Government (2016-2018), focusing on supervised internship program. The program is guided by pragmatism in the conception of teacher training. It points to some elements of criticism towards the program, indicating components of resistance to a policy of professionalization and training of education workers, in the epistemology of praxis, in the terms argued by the area of education and
\end{abstract}

* É doutora em Educação pela Universidade Federal de Goiás. É professora adjunta da Universidade de Brasília no Departamento de Administração e Planejamento da Faculdade de Educação e no Programa de Pós-graduação em Educação. Coordena o Grupo de Pesquisa sobre Formação e Atuação de Professores/ Pedagogos (GEPFAPe). E-mail:<katiacurado@unb.br>. 
by the National Association for the Professional Educators Formation (Anfope).

Keywords: Teacher Training. Educational policies. Epistemology of praxis.

RESUMEN: El texto analiza las políticas campo de la capacitación, propuestas en el actual Gobierno Federal (2016-2018), con foco en el programa de Residencia Pedagógica. El programa se orienta por el pragmatismo en la concepción de capacitación docente. Se apunta a algunos elementos de crítica a los programas, indicando elementos de resistencia para una política de capacitación y profesionalización de los trabajadores de la educación, en la epistemología de la praxis, en los términos defendidos por el área de Educación y por la Asociación Nacional por la Capacitación de los Profesionales de la Educación (Anfope).

Palabras clave: Capacitación docente. Políticas educacionales. Epistemología de la praxis.

\section{Introdução}

Política Nacional de Formação de Professores foi lançada pelo Governo Michel
Temer em outubro de 2017. A proposta deste artigo é abordar, respectiva-
mente, uma análise sobre o Programa de Residência Pedagógica (PRP) e sobre a Base Nacional Comum Curricular (BNCC) como elementos delineadores da Formação de Professores, para os quais reiteramos o posicionamento de crítica e de resistência junto com outras entidades cientificas, dentre as quais destacamos: a Associação Nacional dos Pesquisadores de Educação (Anped), a Associação Nacional pela Formação dos Profissionais da Educação (Anfope), e a Associação Nacional de Política e Administração da Educação (Anpae).

A Residência Pedagógica foi lançada como programa de governo, por meio de Edital, para orientar a política de formação inicial e continuada de professores da educação básica, submetendo as licenciaturas à Base Nacional Comum Curricular. A proposta indica uma reformulação do atual modelo de estágio supervisionado dos cursos de Licenciatura, das diversas Instituições de Educação Superior (IES), os quais estarão se submetendo aos critérios do Edital, cujos elementos apontam para

[...] a criação da Base Nacional de Formação Docente. Essa base, que vai nortear o currículo de formação de professores no país, terá em sua proposta a colaboração de estados, municípios, instituições formadoras e do Conselho Nacional de Educação- CNE (MEC, 2017). 
A ação do Governo nas políticas de formação vem se caracterizando pela fragmentação, com sucessivas reformas e mudanças que apresentam dimensões diferenciadas de profissionalização nos conhecimentos e dimensões científicas - técnicas, éticas, estéticas e culturais -,na formação inicial e continuada (FREITAS, 2007). Fica evidenciado, portanto, que há diferentes embates nas ações e programas de formação de professores propostos pelo Estado e que estes envolvem pesquisadores, movimentos sociais e entidades contra as ações de adesão do governo a uma política neoliberal e influenciada por organismos internacionais.

A justificativa da necessidade de formação pela qualidade da escola, no atendimento à juventude, na natureza da relação teoria e prática, e pelo processo de valorização docente, não se evidencia nos programas propostos pela política de formação de professores. Pois, nestes programas, não foram estabelecidos padrões consistentes de preparação docente ou uma proposta de subsistema nacional de formação de professores que comporia um conjunto de ações articuladas para pensar a formação inicial e continuada de professores, baseada em um conjunto de princípios comuns.

\section{A construção de políticas educacionais versus capacidades estatais}

Optamos por abordar o conceito de centralidade da noção de "capacidades estatais" para a formulação e implementação de políticas públicas, ressaltado pelo neoinstitucionalismo histórico (COUTINHO, 2013). O que nos parece retomado no atual Governo Federal, ao contrário das perspectivas que enfatizam a captura do Estado e sua fragilidade diante de grupos de interesse ou classes sociais, é o neoinstitucionalismo histórico, que enfatiza a "autonomia relativa" do Estado, que tem espaço próprio para atuação e desenvolvimento de suas capacidades, mesmo sendo permeável a pressões externas e internas (ARRETCHE, 1995). De acordo com esta perspectiva, exatamente porque os Estados modernos têm autonomia e interesses próprios - além de contar com capacidade para planejar, administrar e extrair recursos da sociedade - é que puderam ser desenvolvidos os modernos programas sociais.

Essa abordagem ressalta a centralidade das burocracias estatais na formulação e na implementação de políticas. Segundo essa perspectiva, as próprias capacidades estatais podem ser medidas pelo grau de burocratização e de insulamento das burocracias. Assim, quanto mais insuladas das influências da sociedade, maior seria sua capacidade de formulação e implementação de políticas (ARRETCHE, 1995). Segundo Coutinho (2013), a "capacidade estatal" é definida na capacidade de um Estado realizar transformações em múltiplas esferas, sendo que os estudos mais frutíferos são aqueles que focalizam as políticas públicas. Nessa lógica, as capacidades estatais referem-se aos recursos administrativos, financeiros e aos acordos disponíveis para moldar intervenções por meio de políticas. 
As capacidades estatais variam, consideravelmente, em diferentes áreas de políticas. Neste texto, abordamos as políticas educacionais, especificamente as que se referem à formação de professores, que, no Governo Temer, têm sido inseridas como estratégias de realizações dos objetivos governamentais, diretamente na esfera educacional e, indiretamente, em diferentes esferas da administração e expansão do capital, bem como do controle social.

Nesse contexto, as capacidades estatais em contraposição ao conceito de governança expressam de forma mais adequada o atual momento político, já que a relação entre as organizações do setor público, do setor privado e da sociedade civil não são fundamentais para a efetividade do governo, e, sim, para a existência de uma burocracia estatal competente e corporativamente coerente (HUERTA, 2008).

Nas palavras de Rhodes (1996):

Governança significa uma mudança no sentido da atividade governamental, referindo-se a novos processos de governo, ou a renovadas condições para o exercício do poder e para a organização estatal, ou a novos métodos por meio dos quais a sociedade é governada (RHODES, 1996, p. 652).

Portanto, a abordagem tradicional das capacidades estatais, neste momento, se sobrepõe às noções contemporâneas de governança. Isso não significa a exclusão dos vários atores presentes na definição de políticas de Estado, entretanto, no momento do considerado Estado de exceção, tais influências e convergências colocam-se situadas em grupos hegemônicos:

[...] tende a se apresentar cada vez mais como o "paradigma de governo dominante na política contemporânea", seja nas democracias ou nos regimes totalitários, "como um patamar de indeterminação entre democracia e absolutismo" (AGAMBEM, 2004, p. 13).

Deste modo, entende-se que as capacidades estatais precisam ser analisadas sob duas dimensões: i) Técnico-administrativa, a qual envolve as capacidades derivadas da existência e funcionamento de burocracias competentes e profissionalizadas, dotadas dos recursos organizacionais, financeiros e tecnológicos necessários para conduzir as ações de governo de forma coordenada; (ii) Político-relacional, associadas às habilidades e aos procedimentos de inclusão dos múltiplos atores (sociais, econômicos e políticos), de forma articulada, nos processos de políticas públicas, visando à construção de consensos mínimos e de coalizões de suporte aos planos, programas e projetos governamentais. Enquanto a primeira dimensão pode ser associada às noções de eficiência e eficácia, a segunda está relacionada com as ideias de legitimidade, de aprendizagem e de inovação nas ações dos governos, portanto, legitimada na governança, cuja efetividade se encontra fragilizada, enquanto a primeira se apresenta fortalecida no estado de exceção. 
Além disso, as propostas apresentadas nas políticas educacionais de formação de professores sugerem um campo profícuo de políticas públicas, sobre as estruturas das capacidades estatais versus a questão de governança, no Brasil do Governo Temer. A análise de conjuntura nos permite corroborar tais afirmativas. Uma análise de conjuntura é um retrato dinâmico de uma realidade e não uma simples descrição de fatos ocorridos em um determinado local e período. Ela deve ir além das aparências e buscar a essência do real. Porém, a realidade mundial, nacional ou local é multifacetada, o que torna difícil sua apreensão à primeira vista. O desafio de qualquer análise de conjuntura é compreender as inter-relações das partes que formam o todo, pois a totalidade é um conjunto de múltiplas determinações. Neste sentido, a análise de conjuntura funciona como um mapa que nos permite 'viajar' na realidade.

A conjuntura não tem autonomia absoluta em relação à estrutura, a qual continua sendo determinante para se entender a lógica dos acontecimentos políticos e econômicos. Nesta estrutura, o fundante são as relações de produção, e nesse momento das relações de produção capitalistas a conjuntura apresenta sempre algo diferente, numa noção restrita de 'novo'. Isto porque, a correlação de forças e de interesses varia em determinados momentos políticos. A margem de manobra dos atores, portanto, da capacidade estatal na esfera da conjuntura, é relativa. Ou seja, ela é determinada pelas limitações da estrutura. Achar que essa margem é ilimitada e que os atores podem fazer o que quiserem, mesmo em estado de exceção, é incorrer numa espécie de voluntarismo com consequências práticas no campo social e político.

Sendo assim, a conjuntura é determinada pelas alianças econômicas e políticas em um determinado período histórico. No momento, nosso modelo político - presidencialista - vive duas grandes crises: i) Mudança brusca do sistema de alianças entre Poder Executivo, Poder Legislativo e Poder Judiciário e; ii) Regime multipartidário com 32 legendas e outras em formação. Além disso, há uma crise financeira externa, a qual impacta o Mercosul com o agravamento financeiro em vários desses países. A China, por exemplo, desacelerou sua economia e desvalorizou o Yuan. E, para piorar, o Banco Central norte-americano cogita aumentar as taxas de juros, provocando uma revoada dos investimentos para os títulos do Tesouro americano.

Diferentemente das crises econômicas que são cíclicas - com começo, meio e fim -, a crise política depende do florescimento e da afirmação de um novo grupo, de uma nova (velha) hegemonia. É o que parece estar acontecendo no contexto atual, do qual emergem grupos ideológicos representantes de uma política conservadora. No Brasil, a sensação que se tem é que há um esgotamento de um ciclo econômico e de um ciclo político.

As características da crise política, econômica e financeira expressam-se na reforma da Previdência, no congelamento de salários, no aumento de impostos, na redução de benefícios e de direitos. Por consequência, produz desemprego, queda do salário real, queda da arrecadação, retração das atividades econômicas, altas taxas de juro, recessão 
e aumento de impostos. Neste conjunto de ações, os principais beneficiados são os agentes do mercado financeiro, sobretudo, os portadores de títulos da dívida pública interna, e, também, os exportadores ligados ao agronegócio, devido à desvalorização do real e o aumento do dólar.

Na impossibilidade da análise totalizante da conjuntura no espaço deste texto, fiquemos com alguns elementos centrais já apontados. Assim, é preciso perceber que: se nos Governos Dilma-Lula havíamos assistido a certo giro à esquerda, esse giro foi modesto em seus resultados (DOMINGUES, 2015). Contudo, este giro trouxe a possibilidade de governança, tendo em seu centro políticas de equidade que suavizaram de forma humanitária, e economicamente estimulante, as agruras das massas de miseráveis da região mais desigual do mundo (DOMINGUES, 2015). Implicou, ainda, maior centralidade de Estados na perspectiva da governança, sem que a igualdade, propriamente, tenha sido alcançada.

Tais mudanças não foram estruturais e implicaram uma agenda frágil de políticas sociais, sem reverter elementos, tais como: a revisão da dívida pública e do sistema tributário; a mudança da estrutura de impostos, fazendo-a progressiva - baseada na riqueza -, ao invés de basear-se nos rendimentos do trabalho; a reforma agrária, acompanhada do financiamento dos pequenos produtores e das cooperativas; o rompimento do oligopólio de comunicação que compromete o discernimento; e o apoio à elevação do Mercado Comum do Sul (Mercosul). Assim, a crise estrutural aprofundou as contradições e permitiu o impeachment, bem como o Governo Temer como forma de "poder ilegítimo legitimado", com um objetivo muito claro: colocar o Brasil na agenda neoliberal.

Esta breve síntese dos interesses econômicos, políticos e geopolíticos do capitalismo neoliberal - em sua etapa de crise estrutural -, em especial no Brasil, nos permite compreender o momento da política atual no Governo Temer e algumas de suas ações, compreendendo-as na perspectiva da capacidade estatal e no distanciamento do conceito de governança. A questão é: como tais elementos reverberam na política de formação de professores?

Já desde a década de 1990, apresentou-se recorrentes discussões sobre a formação de professores como elemento fundamental no processo de qualificação da educação básica, sendo esta, na perspectiva do capital, considerada questão estratégica para a construção de cidadania e o desenvolvimento da Nação. Tal concepção está presente na argumentação das organizações internacionais que cobram dos países, em troca de diferentes apoios, principalmente o financiamento, o avanço das políticas de formação de professores, visando melhorar os índices nos resultados de avaliações e no perfil do cidadão a ser formado. Moraes (2003) analisa o perfil desse profissional na demanda de tais políticas educacionais:

[...] versatilidade, capacidade de inovação, comunicação, motivação, destrezas básicas, flexibilidade para adaptar-se às novas tarefas, habilidades de cálculo, ordenamento de prioridades e clareza na exposição, que deveriam ser construídas na Educação Básica (MOARES, 2003, p.63). 
Manifestações deste teor, sobre a formação de professores, reaparecem na Organização das Nações Unidas para Educação, Ciência e Cultura/UNESCO (2015), na Organização Internacional do Trabalho/OIT (2012) e na pesquisa TALIS (Teaching and Learning International Survey/2014) quando estas analisam o perfil de professor necessário para o processo de mudança na educação, bem como seu lugar na sociedade. Portanto, no Brasil, com efeito, as decisões de Governo foram tecendo um quadro conceitual, a partir das relações internacionais e nacionais, as quais permitiram as escolhas e formatos, do que formar, e para qual formação de professores. A questão estrutural nos permite tornar visível a força dos "contextos de influência" (BALL, 2008) e das agências mundiais que criam os parâmetros de qualidade para a educação e formação de professores, aproximando-os do ideário do mercado, tanto na linguagem, quanto nas estratégias de implementações de ações.

\section{O Programa de Residência Pedagógica e a Base Nacional Comum Curricular}

Segundo informações no site do Ministério da Educação (MEC) e no Edital de 06/2018 da Coordenação de Aperfeiçoamento de Pessoal em Nível Superior (Capes), o Programa de Residência Pedagógica é uma das ações que integram a Política Nacional de Formação de Professores e tem por objetivo induzir o aperfeiçoamento do estágio curricular supervisionado nos cursos de Licenciatura, promovendo a imersão do licenciando na escola de educação básica, a partir da segunda metade de seu curso. Aimersão acontecerá na escola de educação básica pública, a ser definida pela rede de ensino municipal e/ou estadual. Entre outras atividades, será organizada pela regência de sala de aula e intervenção pedagógica, acompanhadas por um professor da escola com experiência na área de ensino do licenciando, denominado preceptor, e orientadas por um docente da instituição formadora, que pode ser pública ou privada. As Instituições de Ensino Superior serão selecionadas por meio de edital público nacional, para apresentarem projetos institucionais de residência pedagógica.

A Capes indica que o Programa de Residência Pedagógica, articulado aos seus demais programas, compõem a Política Nacional de Formação dos Profissionais da Educação Básica, tendo como premissas básicas o entendimento de que a formação de professores nos cursos de Licenciatura deve assegurar aos seus egressos habilidades e competências que lhes permitam realizar um ensino de qualidade nas escolas de educação básica.

Os objetivos apontados neste Programa, são: i) Aperfeiçoar a formação dos discentes de cursos de Licenciatura, por meio do desenvolvimento de projetos que fortaleçam o campo da prática e conduzam o licenciando a exercitar, de forma ativa, a relação entre teoria e prática profissional docente, utilizando coleta de dados e diagnóstico sobre o 
ensino e a aprendizagem escolar, entre outras didáticas e metodologias; ii) Induzir a reformulação do estágio supervisionado nos cursos de Licenciatura, tendo por base a experiência de residência pedagógica; iii) Fortalecer, ampliar e consolidar a relação entre a IES e a escola, promovendo sinergia entre a entidade que forma e a que recebe o egresso da Licenciatura, e estimulando o protagonismo das redes de ensino na formação de professores; iv) Promover a adequação dos currículos e propostas pedagógicas dos cursos de formação inicial de professores da educação básica às orientações da Base Nacional Comum Curricular (BNCC).

A implementação do Programa de Residência Pedagógica, anunciado pelo MEC e desenvolvido pela Capes, causa estranheza e, contraditoriamente, aponta para a forma de política instituída no Governo, ao ignorar os mecanismos existentes em sua própria estrutura pelos quais são viabilizadas discussões democráticas com a comunidade acadêmica e científica da educação básica, pois deixa de convocar e dialogar com o Conselho Técnico Científico da Educação Básica (CTC), criado em 2007, quando a Capes incorporou a formação de professores para a educação básica como uma de suas responsabilidades. Este CTC foi fortalecido no contexto do Decreto nº 6.755 de 2009, que instituiu a Política Nacional de Formação dos Profissionais da Educação Básica, como instância responsável pela análise das políticas e programas de formação de professores (HELENA FREITAS, 2018).

Um segundo elemento de análise problematiza que o MEC, por sua vez, ao instituir o Programa de Residência Pedagógica, ignora as experiências exitosas de residência já existentes em nosso país - como a da Unifesp, criada em 2009 - e a Residência Docente do Colégio Pedro II, instituída pela própria Capes (HELENA FREITAS, 2018). O estudo realizado por Araújo e Curado Silva (2016), baseado em uma pesquisa bibliográfica que abrangeu o período de 2000 a 2014 -, descreve três modelos de residência docente que estão acontecendo no País.

A primeira experiência no Brasil vem sendo desenvolvida pelo Colégio Pedro II, no Rio de Janeiro. Criada no ano de 2011, teve seu início no ano de 2012. A Residência Docente do Colégio Pedro II ocorre na forma de um projeto de formação continuada, pela qual busca-se aperfeiçoar a formação do professor de educação básica das redes públicas do Rio de Janeiro. A proposta equivale a de uma pós-graduação lato sensu e tem o objetivo de capacitar o docente recém-formado, desenvolvendo estratégias pedagógicas associadas a trabalhos acadêmicos (pesquisas), buscando o aprimoramento da capacidade profissional adquirida na graduação, aperfeiçoando a atuação desse docente nas atividades práticas e na totalidade do ambiente de escola pública.

A segunda experiência é um projeto de residência docente realizada pelo Centro Pedagógico da Universidade Federal de Minas Gerais (UFMG), cuja referência foi o Programa do Colégio Pedro II, no Rio de Janeiro. Este projeto, busca proporcionar aos professores, em exercício na rede pública, experiências e práticas pedagógicas. O programa 
constitui, dessa forma, uma política de formação que articula as reflexões acadêmicas e os desafios cotidianos de uma escola de ensino fundamental, de forma ampliada para a rede pública de educação básica mineira.

A terceira experiência é um projeto-piloto, em desenvolvimento no Colégio Visconde de Porto Seguro, localizado em Morumbi, São Paulo (SP). O "Programa de Residência Docente" teve início no ano de 2015, sendo inspirado pelo curso de formação de professores desenvolvido na Alemanha. Com duração de um ano, é destinado a professores e a futuros docentes que pretendem atuar no Colégio Visconde de Porto Seguro, no ensino fundamental e ensino médio. A literatura indica que há outras experiências, as quais, pelo objetivo do artigo, não nos cabe aqui detalhar. Nossa intenção é demonstrar que experiências foram ignoradas ou superficialmente citadas, como no caso da Unifesp.

Todas as experiências mencionadas e as discussões históricas de entidades, entre elas, Anfope, Anpae e Anped, foram negadas, em detrimento da construção de um Programa de Residência que se revela de caráter pragmático, principalmente, por dois elementos de análise: a concepção de currículo e da formação da educação básica vinculada a BNCC; e a proposta de articulação da teoria e prática tomadas como dadas em espaços distintos. Frente a essa realidade, elencamos alguns elementos que revelam a concepção do Programa de Residência Pedagógica, enquanto políticas de formação de professores.

» A análise que empreendemos, junto com a Anfope e outra entidades, é que esta vinculação ao currículo, aos programas de formação e ao currículo da educação básica, permite a relação direta com avaliações de larga escala e, portanto, uma padronização e quantificação que desconsideram os processos de ensino e aprendizagem de diversos conteúdos, elaborados, ricamente, no interior das escolas, pelos quais são contempladas a diversidade e pluralidade política, econômica, social e cultural do País, em suas distintas regiões e localidades. Além disso, o privilégio direcionado a duas disciplinas específicas reforça o intuito de contemplar a adequação à BNCC e ao Programme for International Student Assessment (Pisa) como um estudo comparado, fragmentando as dimensões e a importância das diversas áreas de conhecimento, bem como fragilizando a importância da função social da escola, dentre as quais transformar o senso comum em conhecimento científico, histórico e filosófico para emancipação do sujeito histórico.

» A BNCC será usada para padronizar e alinhar a formação inicial e continuada dos professores (em formação e em exercício), como já se nota com a recente instauração do Edital de Residência Pedagógica, pelo MEC. O programa de Residência Pedagógica torna-se uma estratégia intrínseca para o implemento imediato e mediato da BNCC nos programas de formação inicial, nos projetos de formação docente e nos projetos políticos pedagógicos das diversas escolas. 
» A política proposta estagna no discurso de que a formação de docentes, nos cursos de Licenciatura, é teórica e oferece pouca prática, partindo de um conceito que desarticula teoria e prática como espaços diferenciados, e que não avança quanto às críticas e análises, necessárias sobre a formação de professores, mas que, no entanto, fazem fragmentar e separar a teoria da prática, reduzindo o conhecimento pedagógico à mera aplicação técnica dos conceitos mercantis da BNCC.

» A padronização da formação social, frente à exigência de elaboração de 'atividades' - envolvendo as competências, os conteúdos das áreas e dos componentes, as unidades temáticas e objetos de estudo previstos na BNCC, criando e executando sequências didáticas, planos de aula, avaliações e outras ações pedagógicas -, reduzindo a formação de professores.

» A intenção de enfraquecer o conceito da unidade teoria-prática a um conjunto de procedimentos - 'aprender a fazer', 'como fazer', 'como aplicar técnica' -, descompromissado de uma concepção sócio-histórica e emancipadora, aliada à realidade material das condições de trabalho e da vivência cotidiana das escolas e comunidades.

O comprometimento desigual, em termos financeiros e de gestão, em um programa que contempla uma parte inócua e pouco representativa do universo dos estudantes das licenciaturas e a possibilidade de alocamento de fundos públicos para investimento da educação pública relacionados diretamente ao ensino, pesquisa e extensão, para as instituições da iniciativa privada, as quais favorecem a formação aligeirada e rasa de docentes.

» Fere a autonomia universitária ao induzir o referencial curricular da educação básica e ao interferir na proposta de um componente curricular das IES, e na constituição de projetos educacionais que articulem universidade e escola.

» Transfere a mediação das ações de formação docente das IES para um controle direto do MEC/Capes, fragilizando a autonomia universitária e a possibilidade de elaboração de projetos de educação - alternativos e emancipatórios -, substituindo as Diretrizes Nacionais dos Cursos de Licenciatura por um programa de distribuição de bolsas de controle e gestão externa.

» Esse movimento revela, ainda, a fragmentação da unicidade nos esforços pela qualidade na formação de professores, dicotomizando a formação entre estudantes bolsistas e estudantes não bolsistas, além de revelar o insignificante e reduzido alcance dessas iniciativas diante das necessidades históricas de formação de nossos estudantes e professores, provocando a formação desigual. 
Diante de tais elementos, e no quadro da nova (velha) política, entendemos ser necessário toda forma de resistência articulada aos movimentos sociais, entidades e associações. Assim, propomos pensar a formação de professores no conceito de Residência Docente, mas com outra base epistemológica de formação, como forma de luta.

\section{A epistemologia da práxis como resistência no Projeto de Residência Pedagógica}

Postos os limites e a concepção das políticas representadas nos editais, e a necessidade de elaborar formas de ação - com intuito de defender a autonomia universitária e primar por uma qualidade na formação de professores -, no sentido unitário da teoria-prática referenciada no trabalho pedagógico como núcleo central da formação, entendemos ser possível, neste momento histórico, a subversão dos projetos institucionais como forma de resistência e manutenção de investimentos públicos em instituições públicas.

Assim, diante da conjuntura em que vivemos e confiante no papel da universidade pública comprometida com a formação de professores - relacionada à realidade social ehistórica da sociedade e comunidades escolares-, posicionamo-nos pela adesão ao Edital, fazendo a disputa pela contemplação de projetos alocados nas instâncias públicas e reforçando a autonomia e isonomia universitária, sem perder de vista os princípios para uma formação docente. Lembremos que a adesão ao Programa Institucional de Bolsas de Iniciação à Docência (Pibid) como programa, nos permitiu a transgressão, ao criar os projetos com autonomia.

Assim, buscamos assumir o conceito de Residência Pedagógica na perspectiva da Pedagogia da Alternância, desenvolvida no início do século XX na França e vinculada a agricultores, visando oferecer uma educação escolar que integrasse os sujeitos em suas culturas locais e possibilitasse o acesso aos conhecimentos significativos e vinculados ao mundo do trabalho, das famílias em pequenas propriedades agrícolas, com o objetivo de produzir uma educação que contribuísse para o desenvolvimento das pessoas e do meio rural (GIGLIO; LUGLI, 2013).

Dessa forma, nossa proposta de RP é uma organização da formação inicial de professores, quiçá continuada, que alterne períodos de aprendizagem em escolas públicas e períodos de aprendizagem em universidades públicas, entendidos como espaços formativos dialéticos, portanto, não podendo ser tomados isoladamente. A concepção de PRP, por nós defendida, busca inspirar-se nessa pedagogia pela renovação, cuja arquitetura permite desenvolver-se pela visibilidade conferida aos tempos e espaços de ensino-aprendizagem, referidos não apenas a modelos abstratos e ou restritamente práticos, mas à ousadia de considerar a vida e o trabalho parte de uma rede de formação na qual a escola e a formação que ela oferece, necessariamente, atuam em colaboração com os ambientes de formação acadêmica (GIGLIO; LUGLI, 2013). A Unifesp (2013) já desenvolve o projeto de RP nesse formato. 
Aliado a essa perspectiva, e de acordo com as posições que a Anfope vem tomando ao longo da história - no intuito da unicidade de princípios constitutivos de uma docência que fomenta a formação social da escola -, faz-se necessário o apontamento de princípios na submissão de projetos e propostas aos Editais nํ․ 06/2018 e n⿳o . 07/2018, como forma de resistência ao projeto neoliberal que toma a frente das políticas e das condutas sociais das escolas de educação básica e superior:

» A educação, e a formação de professores, como espaço público.

» A formação inicial e continuada comprometida com a docência, como atividade intelectual e criadora, propulsora da formação de sujeitos intelectuais e autônomos capazes de reconhecer as diferentes realidades em que os processos educativos tomam forma e lugar.

» A ênfase na base comum nacional para os cursos de formação de professores, como forma de propiciar a unidade e, dialeticamente, a multiplicidade de experiências curriculares (ANFOPE, 1988).

» A epistemologia da práxis como orientadora da formação de professores.

" A Residência Pedagógica na perspectiva da alternância.

» O estudo práxico do currículo, não subscrito na BNCC, mas como movimento de identidade da formação do sujeito, da escola e da educação básica.

» A formação e a valorização docente conforme indicado no Plano Nacional de Educação (2014-2024) e nas Diretrizes Curriculares Nacionais para a Formação de Professores, aprovadas pelo CNE, na Resolução n⿳o. 02/2015.

» A unidade teoria e prática, enquanto postura intrínseca na produção de conhecimento, ou seja, na pesquisa que impregna a organização curricular dos cursos (ANFOPE, 1998).

» A escola e a universidade como espaços formativos dos professores, nos quais há teoria e prática.

" A imersão profissional nos espaços escolares, valorizando o estágio supervisionado como lócus de formação, de valorização e de produção do conhecimento.

» A residência pedagógica como projeto formativo de todos e para todos os estudantes das Licenciaturas.

» O princípio da imersão, tomado no processo de contato sistemático e temporário com as práticas profissionais, no caso, com os professores atuando nos contextos das escolas públicas.

» A articulação da formação de professores com o debate sócio-político da educação. 
Entendemos, assim, ser necessário evitar a ingenuidade e a cooptação (FREITAS, L., 1998), interrogando os intelectuais que compactuam com um projeto cheio de incertezas. Aliás, proclama-se a "era das incertezas", na qual o debate político é perda de tempo para a lógica pragmatista, cega, que caminha guiando o projeto capitalista.

Nesta lógica, sabe-se da impossibilidade de recusar a profissionalização, a formação, a articulação teoria e prática e a gestão democrática, mas é preciso entender estas categorias dentro de cada projeto, pois confusão ideológica e falta de referências, não! A contradição como possibilidade de luta, sim! A contradição como cooptação, não!

E, em contraposição à concepção de uma política que forja a residência pedagógica no saber fazer, a partir da qual, mais uma vez, reafirmamos os pilares fundamentais de uma proposta de formação coletiva na residência pedagógica como alternância de espaços formativos, que buscam garantir autonomia e emancipação, bem como dar condições para que o professor possa atuar como e com a classe trabalhadora, a fim de que todos possam ser governantes.

A luta não é utópica, mas é o caminhar!

Recebido em: 17/05/2018 e aprovado em: 28/07/2018

\section{Notas}

1 A palavra conservador indica substantivo e adjetivo. No primeiro caso, conservador e a derivação conservadorismo implicam um conceito, um conteúdo; no segundo, corresponde à qualificação de atitudes práticas e ideias. Do ponto de vista do uso comum, conservadorismo está ligado à pretensão de manter intacta, de conservar, portanto, de rejeitar o novo e o apelo à mudança, visto como riscos à ordem instituída. A Ciência Política segue procedimento semelhante identificando o conservadorismo às ideias e atitudes que visam à manutenção do sistema político, contrapondo-se às forças inovadoras (BONAZZI, 1992).

\section{Referências}

AGAMBEN, Giorgio. Estado de exceção. Homo sacer II, 1. São Paulo: Boitempo, 2004.

ANFOPE. Documentos finais dos VI, VII, VIII, XI, X, XI, XII, XIII, XIV, XV, XVI, XVII, XVIII Encontros Nacionais da Associação Nacional pela Formação dos Profissionais da educação, 1992, 1994, 1996, 1998, 2000, 2002, 2004, 2006, 2008, 2010, 2012, 2014, 2016.

ARAÚJO, P. R. D.; CURADO SILVA, K. A. C. C. ; CRUZ, S. P. S. Residência Docente. In: IX Encontro Nacional da REDESTRADO. Trabalho docente no século XXI: conjuntura e construção de resistências?, 2017, Campinas-SP, Brasil. Eixo 4 Formação docente: políticas e processos, 2017. v. 1. p. 1-16. Disponível em http://anaisbr2017.redeestrado.org/trabalhos 
ARRETCHE, M. Democracia, federalismo e centralização no Brasil. Rio de Janeiro: Fundação Getúlio Vargas/Fiocruz, 2015.

BALL, S. J. Palestra: Ciclo de Políticas / Análise Política. Rio de Janeiro: Universidade do Estado do Rio de Janeiro (UERJ), 2009. Disponível em: http://www.ustream.tv/recorded/2522493. Acessada em 07/04/2018

BONAZZI, Tiziano. Conservadorismo. In: BOBBIO, N., MATTEUCCI, N.; PASQUINO, G. Dicionário de Política. Brasília: Editora da UnB, 1992, pp. 242-246.

COUTINHO, D. Capacidades estatais no Programa Bolsa Família: o desafio de interação com a assistência social na consolidação do SUAS. Rio de Janeiro: IPEA. 2013.

DOMINGUES, J.M. A conjuntura em duas durações: da crise à disputa do futuro. Revista Trincheiras, Rio de Janeiro: IBASE, n. 1, p. 01- 07, abril de 2015.

FREITAS, Helena. De como MEC e CAPES impõem o aligeiramento da formação e a desprofissionalização dos professores. Campinas, 07 de março de 2018. Díspolnível em: https:// formacaoprofessor.com Acesso em: 12 de mai. de 2018.

FREITAS, L. C. Neotecnicismo e formação do educador. In: ALVES, Nilda (Org.). Formação de professores, pensar e fazer. São Paulo: Cortez, 1998.

GIGLIO, Célia Maria Benedicto; LUGLI, Rosário Silvana Genta. Diálogos pertinentes na formação inicial e continuada de professores e gestores escolares. A concepção do Programa de Residência Pedagógica na UNIFESP. Cadernos de Educação, Pelotas: UFPel, n. 46, p. 62-82, set./dez. 2013.

HUERTA, A. Una ruta metodológica para evaluar la capacidad institucional. Política y Cultura, México:UAM, n. 30, p.119-134, enero 2008.

MORAES, Maria Célia (Org.). Iluminismo às avessas: produção de conhecimento e políticas de formação docente. Rio de Janeiro: DP\&A, 2003.

ORGANIZAÇÃO INTERNACIONAL DO TRABALHO/OIT. O que é trabalho decente? Disponível em: http://www.oitbrasil.org.br/content/o-que-e-trabalho-decente Acesso em: 19/03/2012.

RHODES, R. The New Governance: governing without government. Political Studies, Cambridge: Blackwell Publishers, n. 44, p.652-667, 1996.

TALIS, 2014. Questionários dos diretores e professores (2012-13). Disponível em: http://portal.inep. gov.br/web/talis/resultados. Acesso: 10/01/2015.

UNESCO. Educação para todos fazendo face aos nossos compromissos coletivos - Fórum Mundial de Dakar. UNESCO: Brasília, 2000. Disponível em: www. unesco.org.br/publicações/livros/ educatodosdakar/mostra_padrao>. Acesso em: 17 jan. 2006.

UNIFESP. Projeto Pedagógico do Curso de Pedagogia (2006-2010) da UNIFESP, disponível em http:// humanas.unifesp.br/rep/cursos/pedagogia_projeto_pedagogico.pdf Acesso em abril de 2013. 